\title{
ANALISIS MESIN SEPEDA MOTOR 4 LANGKAH ELECTRONIC FUEL INJECTION DENGAN MENGGUNAKAN PIGGYBACK
}

\author{
Muhammad Reza Habibi ${ }^{1}$, Margono Sugeng ${ }^{2}$ \\ Program Studi Teknik, Universitas Pembangunan Nasional "Veteran" Jakarta, Jakarta Selatan 12 \\ Email $^{2}$ : margono.s@istn.ac.id
}

\begin{abstract}
The need for motorized vehicles at this timeis very high. It can be seen from the increasing number of motorized vehicles that have sprung up with various variations and innovations. Motorized vehicles are needed as a means of transportation to support dayto-day activities both to workplaces, schools, sending goods and so on because they are faster and more efficient and fuel efficient. However, the performance capability of motorized vehicles will experience a decline from all aspects, especially the performance of the engine, due to the use or behavior of our use of the motorbike. One way to restore even improve the performance of the motorbike by giving a device to the control unit system in the form of Piggyback, so that the performance of the motorbike will return like the new one and even increase. To be able to find out the performance of the engine before and after using Piggyback, a motor test was performed on the engine by dynotest on the dynamometer. So this reason the author can analyze how much changes in power, torque and fuel to air ratio occur.
\end{abstract}

Kata kunci: Perfomance, Piggyback,Dyno test, Dynamometer

\section{PENDAHULUAN}

Kebutuhan akan kendaraan bermotor pada saat ini sangatlah tinggi. Dapat diketahui dari semakin banyaknya kendaraan bermotor yang bermunculan dengan berbagai variasi dan inovasi. Yang menyebabkan persaingan diantara produsen kendaraan bermotor berlomba-lomba untuk menciptakan serta menarik pangsa (konsumen) sehingga memenuhi kriteria kendaraan bermotor yang dibutuhkan sebagai alat transportasi demi menunjang kegiatan sehari-hari, baik menuju tempat kerja, sekolah, mengirim barang dan sebagainya dikarnakan lebih cepat dan efisien. Maka sebagian orang akan memilih sepeda motor yang mempunyai tenaga besar, irit bahan bakar dan ramah lingkungan.

Seiring waktu berjalan, Kemampuan performa kendaraan bermotor akan mengalami penurunan dari segi performa terutama performa dari mesin motor tersebut yang diakibatkan karena pemakaian, ataupun perilaku kita saat menjalankan kendaraan tersebut. Oleh sebab itu maka perlu adanya solusi baru untuk mengembalikan bahkan meningkatkan performa motor tanpa harus merubah mesin.

Salah satu cara untuk mengembalikan bahkan meningkatkan performa mesin dengan memberikan suatu alat terhadap system ECU (Elektronic Control Unit) berupa Piggyback, sehingga performa akan meningkat dan lebih efesien. Untuk dapat mengetahui performa mesin sebelum dan sesudah menggunakan Piggyback, maka dilakukan pengujian terhadap mesin motor. Dari hasil pengujian tersebut akan didapat data-data performa mesin yang diuji apakah terjadi peningkatan atau sebaliknya terhadap mesin.

\section{TINJAUAN PUSTAKA}

Pada hal ini berisi mengenai penjelasan singkat teori motor bakar mengenai mesin PGM-FI (Programmed Fuel Injection),cara kerja Piggyback jenis dan mekanisme kerja mesin tersebut.

\section{Pengertian Dasar Motor Bakar}

Motor bakar adalah salah satu jenis dari mesin kalor, yaitu mesin yang mengubah energi termal untuk melakukan kerja mekanik atau mengubah tenaga kimia bahan bakar menjadi energi mekanik. Energi diperoleh dari proses pembakaran, proses pembakaran juga mengubah energi tersebut dilaksanakan di dalam mesin dan ada dilakukan diluar mesin kalor.

\section{Motor Bensin}

Motor bensin pertama kali ditemukan pada tahun 1876. Motor bensin yang ditemukan oleh Otto menggunakan siklus empat langkah. Dengan penjelasan, setiap empat kali langkah piston menghasilkan satu kali kerja atau tenaga. Sehingga motor empat langkah seringkali disebut dengan sebutan motor Otto.Prinsip kerja dari motor bensin yaitu bahan bakar yang berupa campuran bensin dan 
udara dibakar untuk memperoleh tenaga panas yang selanjutnya digunakan untuk melakukan kerja mekanis.

Teknologi PGM-FI (Programmed Fuel Injection)

PGM-FI adalah kata singkatan dari Programmed fuel Injection atau biasa menyebutnya program bahan bakar injeksi, yang merupakan sebuah sistem penyemprotan bahan bakar yang dalam kerjanya dikontrol secara ektronik sesuai kebutuhan motor bakar, sehingga didapatkan daya motor yang optimal dengan pemakaian bahan bakar yang minimal serta mempunyai gas buang yang ramah lingkungan.

\section{Piggyback}

Piggyback adalah sebuah perangkat elektronik yakni sebuah chip microkomputer yang dipasang pada kendaraan bermotor dengan sistem bahan bakar injeksi dengan dua fungsi utama, menambah tenaga kendaraan, atau mengatur efisiensi penggunaan bahan bakar agar jauh lebih irit.Fungsi dari perangkat tambahan ini adalah digunakan sebagai manipulasi sinyal data yang dikeluarkan oleh ECU mesin kendaraan.

\section{METODOLOGI PENELITIAN Metodologi Penelitian}

Metodologi penelitian yang dilakukan mengikuti diagram alir penelitian seperti ditunjukkan pada Gambar-1.

\section{Proses Pengujian}

Proses pengujian mesin tipe " $H$ " dilakukan dengan untuk mengetahui parameter kemampuannya. Untuk mendapatkan parameter kemampuannya mesin yang akurat dari pengujian yang dilakukan, maka pengujian dilakukan sebagai berikut:

1. Pengujian dilakukan pada kondisi lingkungan yang sama pada setiap pengujian.

2. Data pengujian didapatkan dengan melakukan pengukuran yang menggunakan alat ukur dengan kondisi baik

3. Pengambilan data dilakukan setelah motor penggerak mencapai kondisi steady

4. Mesin yang diuji harus kondisi prima.

5. Prosedur pengujian dibagi menjadi tiga prosedur, yaitu: persiapan pengujian, warming up (pemanasan), tahap pengujian.

\section{Peralatan Pengujian}

Pengujian dilakukan pada dyno test, perangkat mesin uji dan alat ukur yang digunakan sebagai ditunjukan dalam diagram instalasi pengujian yang menerangkan penempatan dan alur kerja pengujian unjuk kerja mesin yang dilakukan.

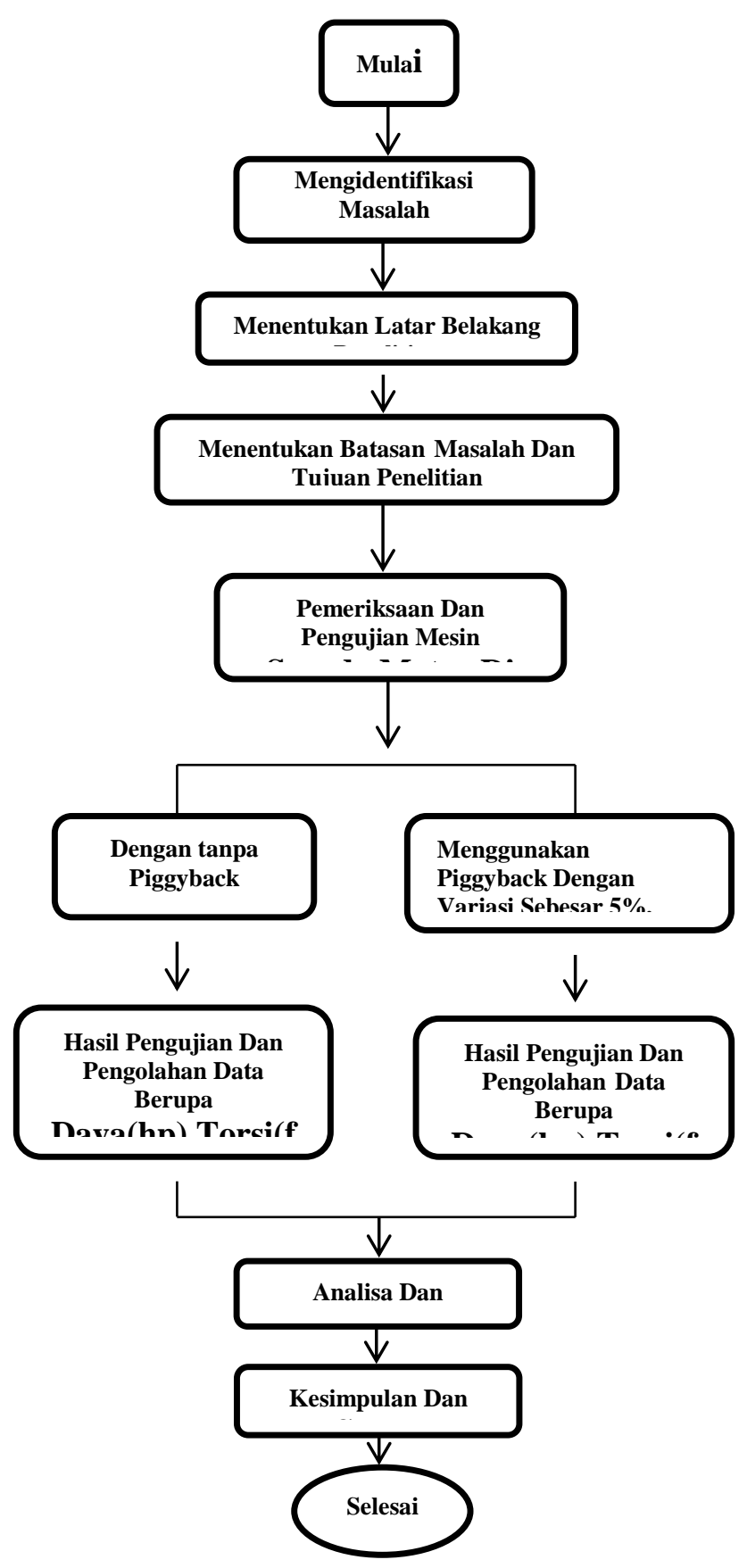

Gambar 1. Diagram Alir Penelitian

\section{Prosedur Pengujian}

Pengujian kemampuan mesin dibagi menjadi tiga prosedur yaitu : persiapan, pengujian, warning up, dan pengujian performa mesin. Pengamatan, pengukuran, dan pengamatan dilakukan secara bertahap dimana dalam satu jenis pengujian dilakukan pada beberapa tinggkat kecepatan putaran mesin konstan, yaitu 5000, 8000, 10.000 dan seterusnya sampai putaran $11.000 \mathrm{rpm}$. Pengujian tahap pertama mesin yang diuji adalah mesin standar, lalu pengujian tahap kedua adalah mesin menggunakan Piggyback dengan variasi 5\%, 10\%, $15 \%$. 


\section{Persiapan Pengujian}

Proses pemasangan alat (setting)untuk pengujian satu jenis memakan waktu sekitar 1 jam agar semua komponen alat pengujian terpasang dengan baik dan menghasilkan data yang sempurna, berikut adalah langkah-langkah persiapan pengujian untuk mesin type k15 DOHC:

1. Siapkan motor yang akan diuji (sudah melakukan servis).

2. Setting data-data yang akan dijadikan sebagai hasil pengujian di monitor.

3. Letakan motor diatas dyno dynanometer.

4. Pasang bracket pada chassis motor dengan penahan.

5. Pasang indikator AFR diujung knalpot.

6. Pasang blower(fan) di depan sepeda motor.

\section{Tahap Pengujian}

Setelah semua peralatan yang diperlukan terpasang dengan baik, mesin dihidupkan untuk pengujian (pemanasan awal). Putaran untuk pemanasan awal ini adalah $5000 \mathrm{rpm}$, selama kurang lebih 5 menit. Pemanasan ini diperlukan agar tercapai kondisi ideal untuk pengujian selanjutnya. Setelah pemanasan awal selesai, putaran mesin diturunkan hingga kondisi idle.Setelah dapat data stasioner pengujian (pemanasan awal), mesin diuji untuk mendapatkan data-data performa awal. Pengujian ini data diambil dari performa mesin pada putaran 5000 sampai $11000 \mathrm{rpm}$.

\section{ANALISIS HASIL DAN PEMBAHASAN DATA Analisis Hasil Data Pengujian}

Berdasarkan hasil pengamatan dilakukan secara bertahap dimana dalam satu jenis pengujian dilakukan pada beberapa tinggkat kecepatan putaran mesin konstan, yaitu 5000, 8000, 10.000 dan seterusnya sampai putaran $11.000 \mathrm{rpm}$. Pengujian tahap pertama mesin yang diuji adalah mesin standar, lalu pengujian tahap kedua adalah mesin menggunakan Piggyback dengan variasi $5 \%, 10 \%, 15 \%$ dapat ditinjau dari beberapa hal dari unjuk kerja mesin yaitu: Daya $(\mathrm{kW})$, Torsi (Nm) dan AFR (berbandingan bahan bakar udara).

\section{Unjuk Kerja Mesin.}

\section{Momen Putar ( Torsi )}

Pada Gambar 2 diatas merupakan data hasil pengujian pada mesin sepeda motor pada saat sebelum menggunakan Piggyback dan sesudah menggunakan Piggyback dengan variasi 5\%, 10\%, dan $15 \%$. Momen putar atau torsi yang dihasilkan

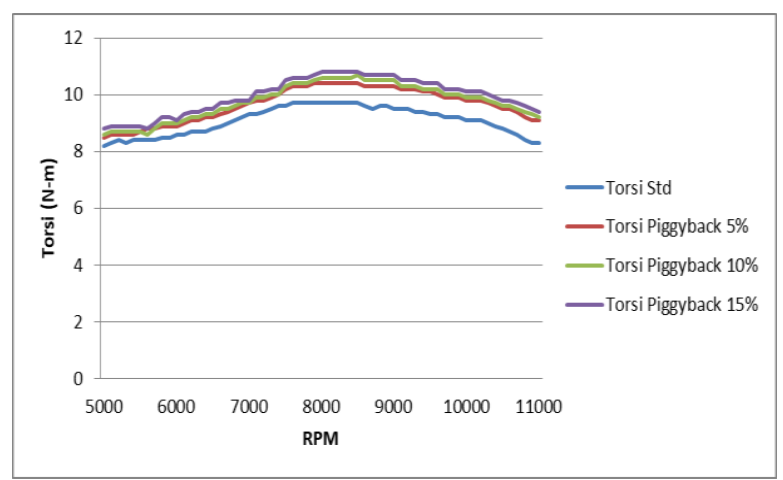

Gambar 2. Grafik Torsi (N-m) sebelum dan sesudah menggunakan Piggyback dengan variasi $5 \%, 10 \%$ dan $15 \%$.

pada saat sebelum menggunakan Piggyback yang ditunjukkan pada Gambar-2 garis berwarna biru, didapatkan torsi maksimum sebesar 9,7 $\mathrm{Nm}$ pada putaran mesin $7600 \mathrm{rpm}$ dan torsi minimum diperoleh sebesar $8,2 \mathrm{Nm}$ pada putaran mesin 5000 rpm.

Dengan menggunakan Piggyback variasi 5\% yang ditunjukkan pada gambar-2 garis berwarna merah. Momen putar atau torsi maksimum yang dihasilkan sebesar 10,4 $\mathrm{Nm}$ pada putaran mesin $7900 \mathrm{rpm}$, dan torsi minimumnya $8,5 \mathrm{~N}-\mathrm{m}$ di putaran mesin $5000 \mathrm{rpm}$.

Selanjutnya pada gambar-2 garis berwarna hijau menunjukkan Piggyback dengan variasi 10\% momen putar atau torsi maksimum yang dihasilkan sebesar 10,7 Nm pada putaran mesin $8500 \mathrm{rpm}$ dan torsi minimum diperoleh sebesar $8,6 \mathrm{Nm}$ saat putaran mesin $5000 \mathrm{rpm}$.

Kemudian menggunakan Piggyback dengan variasi $15 \%$ ditunjukkan pada gambar-2 garis berwarna ungu, momen putar atau torsi maksimum diperoleh sebesar $10,8 \mathrm{Nm}$ pada saat putaran mesin $8000 \mathrm{rpm}$ lalu torsi minimum didapatkan sebesar 8,8 Nm di putaran mesin 5000 rpm.

\section{Daya Poros Efektif (Ne)}

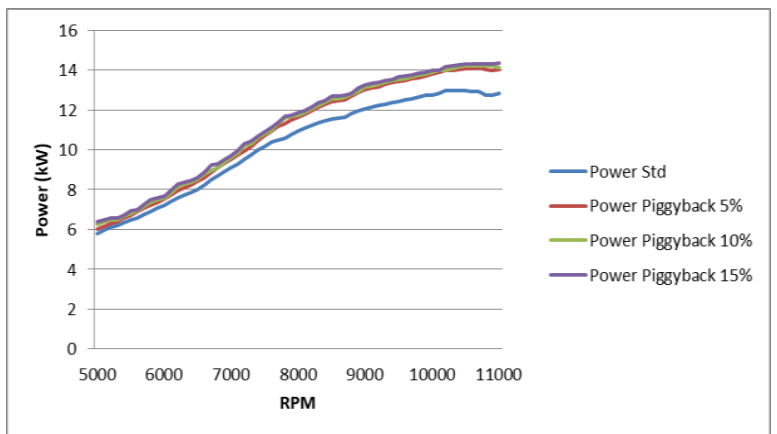

Gambar 3. Grafik Daya (kW) sebelum dan sesudah menggunakan Piggyback dengan variasi $5 \%, 10 \%$ dan $15 \%$. 
Pada grafik diatas merupakan data hasil pengujian pada mesin sepeda motor pada saat sebelum dan sesudah menggunakan Piggyback dengan variasi $5 \%, 10 \%$ dan $15 \%$. Daya poros efektif $(\mathrm{Ne})$ maksimum pada kondisi standar menghasilkan daya sebesesar $12,99 \mathrm{~kW}$ pada putaran mesin $10300 \mathrm{rpm}$ dan torsi minimum $5,786 \mathrm{~kW}$ di putaran mesin $5000 \mathrm{rpm}$ yang ditunjukkan pada gambar-3 garis berwarna biru.

Kemudian dengan variasi Piggyback sebesar 5\% menghasilkan daya poros atau power maksimum sebesar $14,11 \mathrm{~kW}$ pada putaran mesin di $10700 \mathrm{rpm}$ dan power minimum diperoleh $6,005 \mathrm{~kW}$ di putaran mesin $5000 \mathrm{rpm}$, yang ditunjukkan pada gambar-3 pada garis berwarna merah.

Dengan menggunakan Piggyback dengan variasi $10 \%$, power maksimum yang dihasilkan sebesar 14,22 kW pada putaran mesin $10900 \mathrm{rpm}$, dan power minimum didapat $6,265 \mathrm{~kW}$ di putaran mesin $5000 \mathrm{rpm}$ yang terlihat pada gambar-3 garis berwarna hijau.

Selanjutnya dengan menggunakan Piggyback variasi $15 \%$ power maksimum yang dihasilkan sebesar $14,35 \mathrm{~kW}$ pada saat putaran mesin $11000 \mathrm{rpm}$ lalu power minimum didapat sebesar 6,373 kW di putaran mesin $5000 \mathrm{rpm}$. Yang terdapat pada gambar-3 garis berwarna ungu.

\section{Perbandingan Bahan Bakar dan Udara (AFR)}

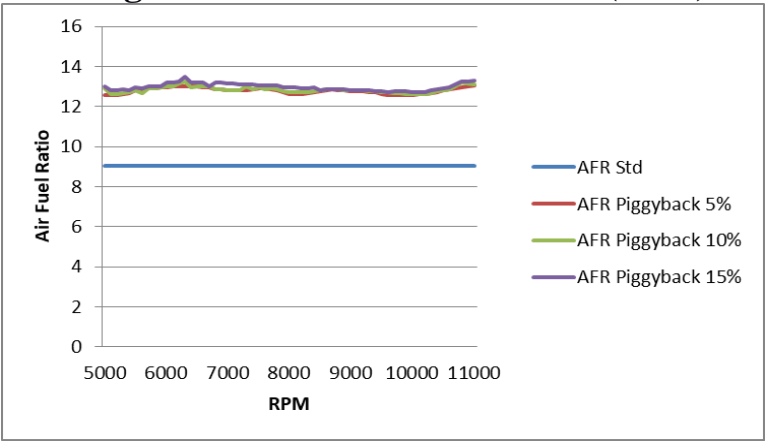

Gambar 4. Grafik AFR (Perbandingan bahan bakar dan udara ) sebelum dan sesudah menggunakan Piggyback dengan variasi 5\%,10\% dan $15 \%$.

Pada grafik diatas merupakan data hasil pengujian pada mesin sepeda motor pada saat sebelum dan sesudah menggunakan Piggyback dengan variasi $5 \%, 10 \%$ dan $15 \%$. AFR (Perbandingan bahan bakar dan udara) maksimum pada kondisi standar menghasilkan AFR sebesar 9,031 : 1 pada putaran mesin konstan disetiap rpm dan torsi ditunjukkan pada gambar-4 garis berwarna biru.

Kemudian dengan variasi Piggyback sebesar 5\% AFR (Perbandingan bahan bakar dan udara) maksimum sebesar 13,03:1 pada putaran mesin di $11000 \mathrm{rpm}$ dan afr minimum diperoleh 12,55 : $1 \mathrm{di}$ putaran mesin 5000 rpm, yang ditunjukkan pada gambar-4 pada garis berwarna merah.

Dengan menggunakan Piggyback dengan variasi 10\%AFR (Perbandingan bahan bakar dan udara) maksimum yang dihasilkan sebesar 13,15:1 pada putaran mesin $10900 \mathrm{rpm}$, dan AFR minimum didapat 12,62:1 di putaran mesin $5000 \mathrm{rpm}$ yang terlihat pada gambar-4 garis berwarna hijau.

Selanjutnya dengan menggunakan Piggyback variasi 15\% AFR (Perbandingan bahan bakar dan udara) maksimum yang dihasilkan sebesar 13,31:1 pada saat putaran mesin $11000 \mathrm{rpm}$ lalu AFR minimum didapat sebesar 12,8 : 1 di putaran mesin $5400 \mathrm{rpm}$ yang dapat dilihat pada gambar-4 garis berwarna ungu

\section{KESIMPULAN}

Dari hasil melakukan pengujian pada mesin sepeda motor elektronik fuel injection merk " $\mathrm{H}$ " tipe k 15 dohc berkapasitas $150 \mathrm{cc}$ setelah dilakukan analisis dengan melakukan serangkaian pengujian saat mesin motor sebelum dan sesudah menggunakan Piggyback dengan variasi 5\%, 10\%, dan 15\%, maka diperoleh hasil kesimpulan sebagai berikut :

1. Momen putar atau torsi maksimum yang dihasilkan oleh mesin sepeda motor dengan keadaan tanpa pemasangan Piggyback ialah 9,7 Nm pada putaran mesin $7600 \mathrm{rpm}$. Sedangkan momen putar maksimum yang dihasilkan setelah pemasangan Piggyback dengan variasi $5 \%$ adalah sebesar $10,4 \mathrm{Nm}$ diputaran mesin $7900 \mathrm{rpm}$. Tertulis 300 rpm dan torsi $0,7 \mathrm{Nm}$ lebih besar dihasilkan dengan menggunakan Piggyback yang artinya mesin k 15 dohc saat putaran mesin 7900 rpm sudah mencapai torsi maksimum dan pemasangan Piggyback dengan variasi $5 \%$ sangat berpengaruh pada perubahan mesin sepeda motor.

2. Momen putar maksimum yang dihasilkan oleh mesin sepeda motor setelah melakukan pemasangan Piggyback dengan berbagai variasi yaitu variasi $5 \%, 10 \%$, dan $15 \%$ menghasilkan torsi sebagai berikut,

a. Torsi maksimum yang dikeluarkan oleh pemasangan Piggyback dengan variasi $5 \%$ sebesar $10,4 \mathrm{Nm}$ pada putaran mesin $7900 \mathrm{rpm}$, sehingga lebih besar $0,7 \mathrm{Nm}$ dan $300 \mathrm{rpm}$ dibandingan dengan sebelum menggunakan Piggyback yang hanya 9,4 Nm di 7600 rpm. 
b. Torsi maksimum yang dihasilkan oleh pemasangan Piggyback dengan variasi $10 \%$ diperoleh $10,7 \mathrm{Nm}$ pada putaran mesin $8500 \mathrm{rpm}$, sehingga lebih besar 1,3 $\mathrm{Nm}$ dan $900 \mathrm{rpm}$ dibandingkan dengan sebelum menggunakan Piggyback sebesar 9,4 Nm di 7600 rpm.

c. Torsi maksimum yang diperoleh penggunaan Piggyback dengan variasi $15 \%$ sebesar $10,8 \mathrm{~N}-\mathrm{m}$ pada putaran mesin $8000 \mathrm{rpm}$, sehingga lebih besar $1,4 \mathrm{Nm}$ dan $400 \mathrm{rpm}$ dibandingkan sebelum menggunakan Piggyback yang hanya 9,4 Nm di $7600 \mathrm{rpm}$.

3. Daya poros efektif maksimum yang dihasilkan oleh mesin sepeda motor sebelum menggunakan Piggyback sebesar 12,99 kW pada putaran mesin $10300 \mathrm{rpm}$ dan setelah melakukan pemasangan Piggyback dengan variasi $5 \%, 10 \%$, dan $15 \%$ menghasilkan daya poros sebagai berikut:

a. Daya maksimum yang dikeluarkan oleh penggunaan Piggyback dengan variasi $5 \%$ sebesar $14,11 \mathrm{~kW}$ pada putaran mesin $10700 \mathrm{rpm}$, sehingga lebih besar $1,12 \mathrm{~kW}$ dan $400 \mathrm{rpm}$ dibandingan sebelum menggunakan Piggyback yang hanya menghasilkan $12,99 \mathrm{~kW}$ di putaran $10300 \mathrm{rpm}$.

b. Daya maksimum yang dihasilkan dari penggunaan Piggyback dengan variasi $10 \%$ sebesar $14,22 \mathrm{~kW}$ pada putaran mesin $10900 \mathrm{rpm}$, sehingga lebih besar $1,23 \mathrm{~N}-\mathrm{m}$ dan $600 \mathrm{rpm}$ dibandingkan sebelum menggunakan Piggyback yang mengasilkan daya sebesar $12,99 \mathrm{~kW}$ pada putaran $10300 \mathrm{rpm}$.

c. Daya maksimum yang diperoleh sesudah pemasangan Piggyback dengan variasi $15 \%$ sebesar $14,35 \mathrm{~kW}$ pada putaran mesin $11000 \mathrm{rpm}$, maka lebih besar $1,36 \mathrm{~kW}$ dan $600 \mathrm{rpm}$ sebelum melakukan pemasangan Piggyback yang hanya sebesar 12,99 $\mathrm{kW}$ di putaran mesin $10300 \mathrm{rpm}$

4. Perbandingan bahan bakar dan udara AFR (Air Fuel Ratio) sebelum menggunakan Piggyback sebesar 9,031 : 1 berlangsung konstan dari awal mesin dihidupkan atau rpm awal hinggal rpm akhir. Sedangkan setelah menggunakan Piggyback dengan variasi 5\%, 10\%, dan 15 $\%$ perbandingan bahan bakar dan udara diperoleh sebagai berikut :

a. Setelah menggunakan Piggyback variasi $5 \%$ perbandingan bahan bakar dan udara tertinggi mencapai $13,03: 1$ pada putaran mesin $11000 \mathrm{rpm}$.

b. Dengan menggunakan Piggyback variasi $10 \%$ perbandingan bahan bakar dan udara tertinggi diperoleh 13,15:1 pada putaran mesin $10900 \mathrm{rpm}$.

c. Selanjutnya setelah menggunakan Piggyback dengan variasi 15\% perbandingan bahan bakar dan udara tertinggi sebesar 13,31: 1 pada putaran mesin $11000 \mathrm{rpm}$.

Dari hasil kesimpulan yang didapat dari analisis pada pengujian mesin sepeda motor 4 langkah electronik fuel injection sebelum dan sesudah menggunakan Piggyback dengan variasi 5\%, 10\%, dan 15\%. Menunjukkan bahwa mesin "H" tipe k15 Dohc berkapasitas 150 cc mengalami kenaikan performa yang sangat singnifikan, dari mulai momen puntir atau torsi, daya poros atau power yang dihasilkan, dan perbandingan bahan bakar udara AFR (Air Fuel Injection) yang mengalami perubahan awal rpm hingga akhir rpm dibandingkan sebelum menggunakan Piggyback.

\section{DAFTAR PUSTAKA}

Hidayat, Wahyu. Motor Bensin Modern, PT RINEKA CIPTA 2012

Pulkrabek, W.W. (2010) Engineering Fundamentals of Internal Combustion Engine, New Jersey. Prentice Hall.

Jalius Jama, Wagino. Teknik Sepeda Motor Jilid 1 dan 2. Penerbit Direktorat Pembinaan Sekolah Menengah Kenjuruan, Jakarta, 2008

Technical Service Division:"Bintang Motor" PT AHASS Bintang Motor 2013

Daryanto, Prinsip Dasar Mesin Otomotif, CV, Aneka Ilmu 2011

Wiranto, Arismunandar. Penggerak Motor Bakar Torak, Edisi 5, Penerbit ITB, Bandung, 2011. http://Alim Syaiful.blogspot.co.id/2012/05/ Sistem PGM-FI Honda.html

http://id.m.wikipedia.org/wiki/PGM-FI Motor Honda

http://montir.wordpress.com/2010/01/03sebenarny a- piggy-back-itu-apa/ 
http://www.mekanikmitsubishi.com/pengertianpiggyback-fungsinya-dan-kelebihan-untukkendaraan.html 